\title{
Synthesis and Characterization of all Possible Diastereoisomers of Alvimopan
}

\section{BEERAVALLI RAMALINGA REDDY ${ }^{1,2}$, MANOJ KUMAR DUBEY', CH.VENKATA RAMANA REDDY ${ }^{2}$ and RAKESHWAR BANDICHHOR ${ }^{\text {* }}$}

\begin{abstract}
${ }^{1}$ APIR \& D, IPDO, Dr. Reddy's Laboratories Ltd. Bachupally, Hyderabad-500090, Telangana, India. ${ }^{2}$ Department of Chemistry, JNTU College of Engineering, JNT University, Kukatpally, Hyderabad-500072, Telangana, India.

*Corresponding author E-mail: rakeshwarb@drreddys.com

http://dx.doi.org/10.13005/ojc/340246

(Received: December 18, 2017; Accepted: January 30, 2018)

\section{ABSTRACT}

Isolation of all possible diastereomers of alvimopan 1 was found to be challenging. In order to perform cut off studies during analytical method development, it was mandatory to synthesize and characterize all the diastereomeric impurities. Here in, our efforts toward the synthesis and isolation of alvimopan (1) diastereomers are discussed.
\end{abstract}

Keywords: Alvimopan, Diastereomers, Resolution, Antagonists.

\section{INTRODUCTION}

Number of biological substances and natural products are found to exist as enantiomeric pairs. In this instance, alvimopan 1 as shown in Fig. 1, has three chiral centers thus it will have theoretically eight diastereomers. Out of these, one of the diastereomers is found to be active as opioid antagonist and prescribed for the treatment of postoperative ileus. In order to establish the percentage content of unwanted diastereomers and define the specifications in the drug substance which is unprecedented hitherto therefore we attempted to synthesize and characterize all possible diastereomers. Here in, we present our strategy which has successfully been executed to obtain four practically feasible diastereomers due to anti relationship at 3 and 4 chiral carbon centers. Interestingly, syn pair was not observed thus other four diastereomers are chemically negated.

Alvimopan ([[2(S)-[[4(R)-(3 Hydroxyphenyl)3R,4-dimethyl-1-piperidinyl] methyl]-1-oxo-3phenylpropyl]-amino]acetic acid 1 dihydrate is an opioid drug used for the treatment upper and lower gastrointestinal recovery following partial or large 
and small bowel resection surgery with primary anastomosis. ${ }^{1}$ The drug is also having the activity towards the treatment of post operative ilieus and chronic idiopathic constipation. ${ }^{2}$

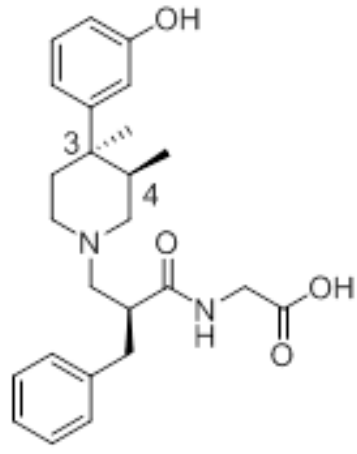

1

Fig. 1. Structure of alvimopan 1

\section{MATERIAL AND METHOD}

All the raw materials, reagents and solvents used in the preparation of the impurities are commercial grade. IR spectra of all four diastereomers were carried out by using Perkin Elmer 2400 FTIR spectrophotometer using $\mathrm{KBr}$ pellet. Mass spectra recorded on 4000-Q-trap LC-MS/MS mass spectrometer. ${ }^{1} \mathrm{H}$ and ${ }^{13} \mathrm{C}$ NMR were recorded in $\mathrm{DMSO}-d_{6}$ at $400 \mathrm{MHz}$ on a unity INOVA (Varian $400 \mathrm{MHz}$ ) FT NMR spectrometer. The chemical shifts are reported in $\delta(\mathrm{ppm})$ relative to TMS $(\delta 0.00)$. The SOR was recorded at $25^{\circ} \mathrm{C}$ at 1.01 concentration in DMSO.

\section{RESULTS AND DISCUSSION}

Alvimopan contain total three chiral centers, which leads to form total eight theoretical diastereomers. Two chiral centers are present in the key starting material 2 and the $3^{\text {rd }}$ one is generated during the preparation of the compound 13. There are various routes of the synthesis were reported for the preparation of alvimopan and its key starting material. ${ }^{3-6}$ The complete synthesis of alvimopan was disclosed by John A Werner et al., and his co-workers. ${ }^{7}$ In the reported synthesis no information was available regarding the diastereomers of alvimopan 1.
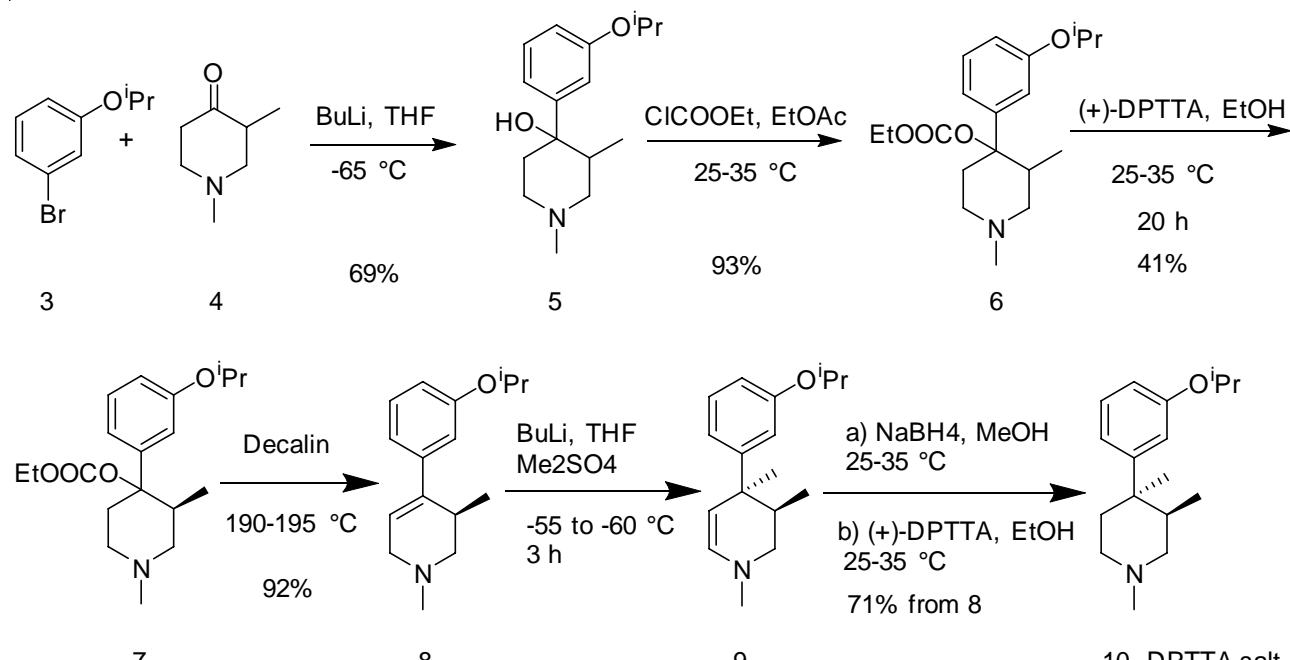

10. DPTTA salt

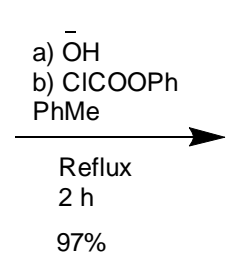<smiles>CCCOc1cccc(C2(C)CCN(C(=O)Oc3ccccc3)C[C@H]2C)c1</smiles>

11

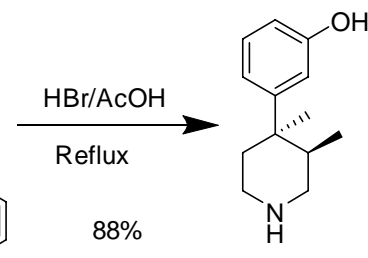

2

Scheme 1. Synthesis of compound 2 


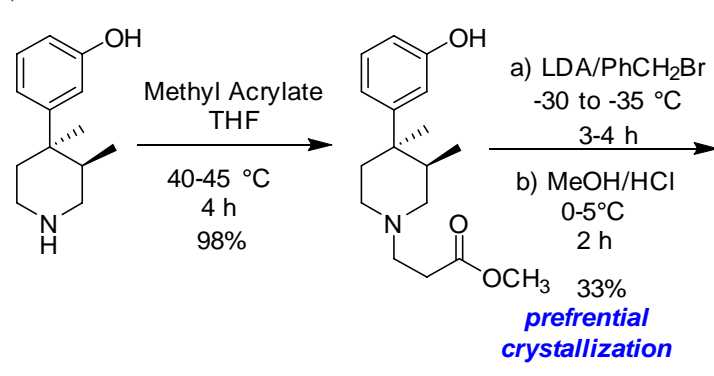

12

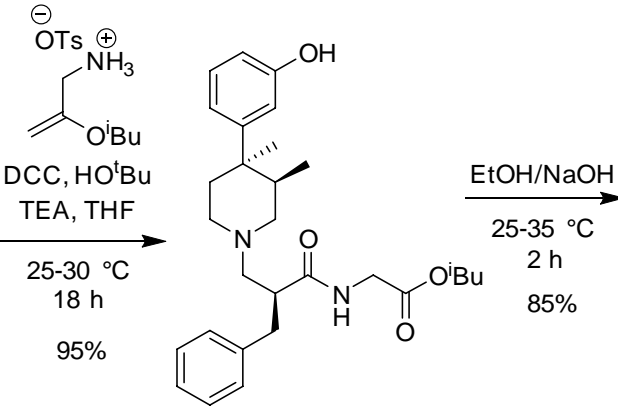

15<smiles>COC(=O)[C@H](Cc1ccccc1)CN1CC[C@](c2ccccc2)(c2cccc(O)c2)[C@H](CO)C1</smiles>

13<smiles>C[C@H]1CN(CC(Cc2ccccc2)C(=O)O)CC[C]1c1cccc(O)c1</smiles>

14

Scheme 2. Synthesis of compound 1

In the synthesis of alvimopan 1, first chiral center was generated during the preparation of the compound 7 by resolution of compound 6 with (+)-diparatoulyl- $D$-tartaric acid. Unwanted isomer of compound 7 which is $7 \mathrm{a}$ can easily be isolated from the filtrate of the compound 7.<smiles>CCCOC(=O)C1CN(C)CCC1(OCC)c1cccc(OCC)c1</smiles>

7<smiles>CCCOc1cccc(C2(OC(=O)OCC)CCN(C)C[C@H]2CC)c1</smiles>

$7 a$
Fig. 2. Structures of wanted (7) and unwanted

(7a) isomers

Alternately, diastereomer $7 \mathrm{a}$ was also synthesized by resolution of 6 with (-)-diparatoulyl-Dtartaric acid. The second chiral center was generated during the preparation of compound 9 by using decalin at higher temperature followed by $n$-BuLi and dimethyl sulfate. Interestingly, this event was found to be stereoselective (near stereospecific) yielding only anti pairs amounting to two enantiomers 9 and $9 a$ as shown in Figure 3.<smiles>CCCOc1cccc(C2(C)C=CN(C)CC2C)c1</smiles>

9<smiles>CCCOc1cccc(C2(C)C=CN(C)C[C@@H]2C)c1</smiles>

$9 a$
Fig. 3. Structures of wanted (9) and unwanted (9a) enantiomers

The $3^{\text {rd }}$ chiral center was generated during the preparation of the compound 13. Due to anti selectivity during methylation towards preparation of 9 or 9 a, it was practically feasible to obtain only four diastereomers (13,13a, 13b and 13c) as shown in Fig. 4. This Fig. also outlines the retrosynthetic approach to obtain all four diastereomers in sequence.

Eventually, by using 13,13a, 13b and $13 \mathrm{c}$ and following the similar sequence featured in Scheme 1, we were able to prepare all the alvimopan diastereomers (1, 1a, 1b and 1c) as shown in Figure 5. 


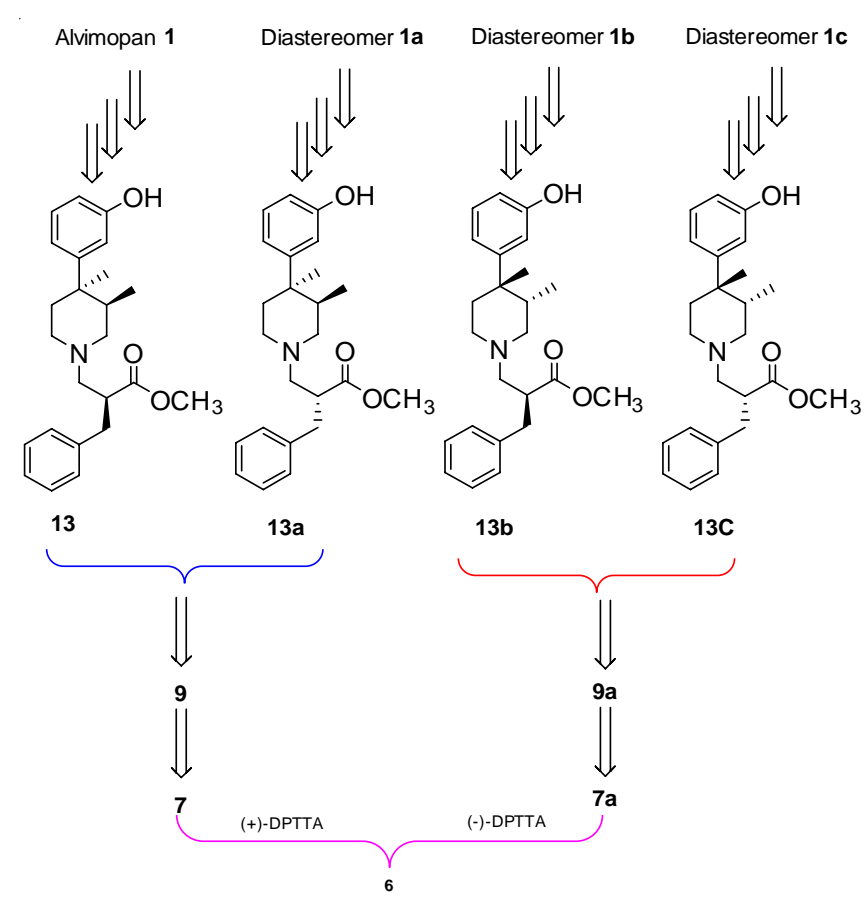

Fig. 4. Retrosynthetic analysis to obtain all four diastereomers starting from 6

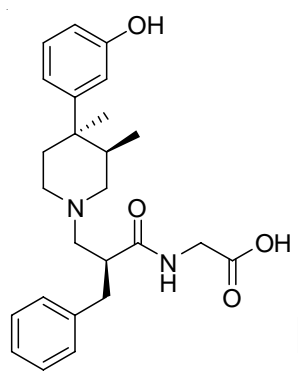

1

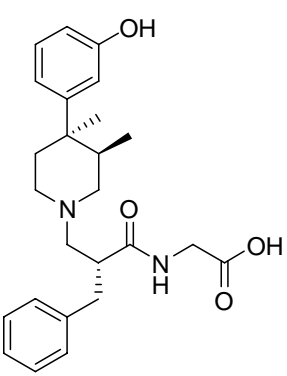

$1 \mathrm{a}$

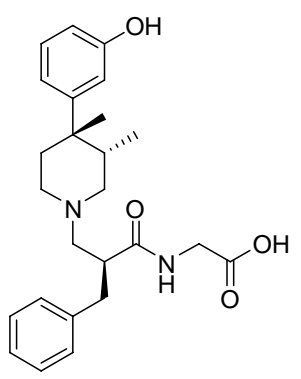

$1 \mathrm{~b}$

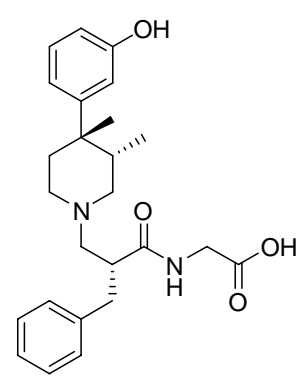

$1 c$

Fig. 5. Structures of all four diastereomers (1, 1a, 1b and 1c) of alvimopan

After synthesis, isolation and characterization, diastereomers and the results are as shown in the we recorded the SOR for alvimopan and its Table 1.

Table 1: SOR and diastereomeric configuration of the alvimopan and its diastereomers

\begin{tabular}{|c|c|c|c|}
\hline S. No. & $\operatorname{SOR}[\alpha]_{D}^{25}(\mathrm{C}=1.01 \mathrm{in} \mathrm{DMSO})$ & Compound & Stereochemical Assignment \\
\hline 1 & $+43.48^{\circ}$ & 1 & Bor R, 3R, 4R \\
\hline 2 & $+53.21^{\circ}$ & $1 \mathrm{a}$ & $\alpha o r$ S, 3R, 4R \\
\hline 3 & $-47.22^{\circ}$ & $1 b$ & ßor R, 3S, 4S \\
\hline 4 & $-52.40^{\circ}$ & $1 c$ & $\alpha o r S, 3 S, 4 S$ \\
\hline
\end{tabular}


In addition to SOR studies we attempted to study the structural features by using Infra-Red spectroscopy. As expected, there were no major changes observed in any of the stretching bands of the functional groups present in the diastereomers as shown in Table 2.

Table 2. IR signals assignment for alvimopan and its diastereomers (values in $\mathrm{cm}^{-1}$ )

\begin{tabular}{lcccc}
\hline $\begin{array}{l}\text { Functional group and } \\
\text { type of vibration }\end{array}$ & Compound 1 & Compound 1a & Compound 1b & Compound 1c \\
\hline OH stretching & 3410.5 & 3423.5 & 3410.1 & 3425.6 \\
$\mathrm{NH}$ stretching & 3207 & 3207.5 & 3209.5 & 3209 \\
Aromatic -CH stretching & 3029 & 3027 & 3030.2 & 3032.1 \\
Aliphatic -CH stretching & 2927 & 2930 & 2978.1 & 2981.9 \\
C=O amide stretching & 1560 & 1593 & 1592.2 & 1593.2 \\
\hline
\end{tabular}

${ }^{1} \mathrm{H}$ NMR and ${ }^{13} \mathrm{C}$ NMR for alvimopan and its diastereomers were recorded by using Varian Mercury plus $400 \mathrm{MHz}$ spectrometer. The solvent used for analysis is DMSO- $d_{6}$. The ${ }^{1} \mathrm{H}$ NMR chemical shifts values were reported on $\delta$ scale in ppm relative to TMS $0.00 \mathrm{ppm}$ and ${ }^{13} \mathrm{C}$ NMR chemical shifts values were reported relative DMSO- $d_{6}$ $\delta=39.50 \mathrm{ppm}$. Structural elucidation for each and every diastereomer was performed by correlating the $\delta$ values of corresponding ${ }^{1} \mathrm{H}$ NMR and ${ }^{13} \mathrm{C}$ NMR featured in Table 3 and 4 . The number assignment was shown in Figure 6.<smiles>C[C@H]1CN(C[C@H](Cc2ccccc2)C(=O)NCC(=O)O)CC[C@@]1(C)c1cccc(O)c1</smiles>

Fig. 6. The NMR number assignment of alvimopan

In order to establish the relative retention time of the diastereomers $1 \mathrm{a}, 1 \mathrm{~b}$ and $1 \mathrm{c}$ with respect to alvimopan 1, a blend sample was injected in the HPLC column. The blend sample HPLC chromatogram were compared with alvimopan 1 HPLC chromatogram. This exercise clearly indicates that all three diastereomers (1a, $1 \mathrm{~b}$ and 1c) are distinctly different than alvimopan 1 as shown in Fig. 7. HPLC analytical conditions are as follows:

\section{Procedure}

1. Column: Chiral pack IC

2. Mobile phase: n-Hexane: Isopropyl alcohol: Ethanol (70:25:5) with 0.2 of diethyl amine.

3. Column: $25^{\circ} \mathrm{C}$.

4. Concentration: $2 \mathrm{mg} / \mathrm{mL}$

5. Wavelength: $273 \mathrm{~nm}$.

6. Detector: UV

The blend chromatogram is shown in Fig. 7 . The retention times of the diastereomers $(1 \mathrm{a}, 1 \mathrm{~b}$ and 1c) and the alvimopan 1 are given in Table 5.

Table 5: The retention and relative retention times of alvimopan and its diastereomers by HPLC

\begin{tabular}{lcc}
\hline Compound & $\begin{array}{c}\text { Retention time } \\
(\mathrm{RT}) \text { Minutes }\end{array}$ & $\begin{array}{c}\text { Relative retention } \\
\text { time (RRT) }\end{array}$ \\
\hline Alvimopan & 16.5 & 1.0 \\
1a & 12.05 & 0.73 \\
1b & 14.89 & 0.90 \\
$1 \mathrm{c}$ & 20.19 & 1.22 \\
\hline
\end{tabular}

The alvimopan prepared by the reported Scheme 1 and the product contains the diastereomers $1 b$ and $1 c$ are at the level of 0.02 and $1 \mathrm{a}$ at the level of 0.12 area percentage. 


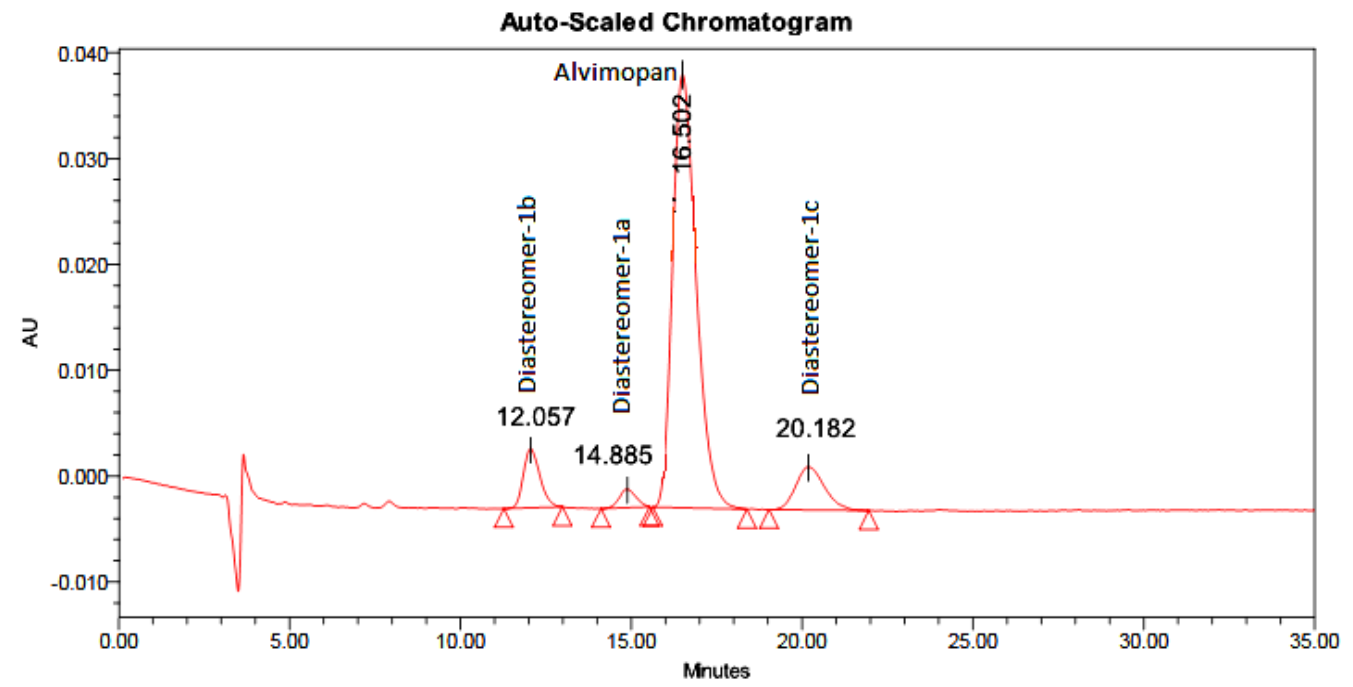

Fig. 7. Blend sample HPLC chromatogram of alvimopan and its three diastereomers

\section{Synthesis of impurities}

All the impurities were prepared synthetically as per the reported sequence of reactions for the preparation of alvimopan shown in Scheme 1.

\section{Synthesis of $1 \mathrm{a}$}

Reaction of 12 with benzyl bromide afforded both 13 and 13 a in 1:1 ratio as shown Scheme 2. The undesired compound 13a was separated from compound 13 by preferential crystallization in methanol. The impurity $13 a$ was isolated from the mother liquor and purified by column chromatography. Impurity 13 a further undergoes the alvimopan reaction sequence (Scheme 2) during the preparation to give rise impurity 1 (1a or $\alpha R, 3 R, 4 R$ isomer) with same similar process efficiency.

\section{Impurity 1b}

During the resolution of compound 6 to obtain compound 7 , undesired isomer 7 a was also found to be co-precipitated along with compound 7. Thereafter, $7 \mathrm{a}$ undergoes transformations involved in the synthesis of alvimopan and eventually afforded impurity 2 . The preparation of impurity 2 can alternately be prepared from 6 by resolving it with (-)-diparatoulyl- $D$-tartaric acid to obtain $7 \mathrm{a}$ as isolated product. With this material, by repeating the alvimopan (1) synthetic sequence it was possible to obtain diastereomeric impurity 2
(Compound $1 \mathrm{~b}$ or $\beta \mathrm{R}, 3 S, 4 S$ isomer) with similar process efficiency.

\section{Impurity 1c}

During the preparation of compound 13 by reacting the compound 12 with benzyl bromide, both 13 and 13 a will form in 1:1 ratios. Similarly the carry forwarded impurity of 12 a forms two different isomers of $13 \mathrm{~b}$ and $13 \mathrm{c}$. Compound $13 \mathrm{~b}$ undergoes further sequence of reactions and ends up as impurity 2 (S, S, S isomer). Similarly the $13 \mathrm{c}$ isomer undergoes the sequence of the reactions and ends up as impurity-3. During the preparation of compound $13 \mathrm{~b}$, the obtained mother liquors purified by column chromatography to obtain pure diastereomeric impurity of $13 \mathrm{c}$. This pure compound made to undergo same reaction sequence of alvimopan (1) proceeded to obtain diastereomeric impurity-3 (1c or $\alpha \mathrm{R}, 3 S, 4 S$ isomer).

\section{Structure Elucidation \\ Alvimopan}

ESI mass spectrum of alvimopan exhibited protonated molecule peak at $\mathrm{m} / \mathrm{z} 425(\mathrm{MH})^{+}$in positive ion mode, indicating the mass of alvimopan is 424 . In ${ }^{1} \mathrm{H}$ NMR of alvimopan, the signal at 9.10 ppm broad singlet corresponding to phenolic $\mathrm{OH}$ proton and another singlet at 5.56-5.58 ppm corresponds to amide proton of $\mathrm{NH}$. The complete NMR signals assignment was given in Table 3. In the IR spectrum, a broad band at $3410 \mathrm{~cm}^{-1}$ for $\mathrm{OH}$ 


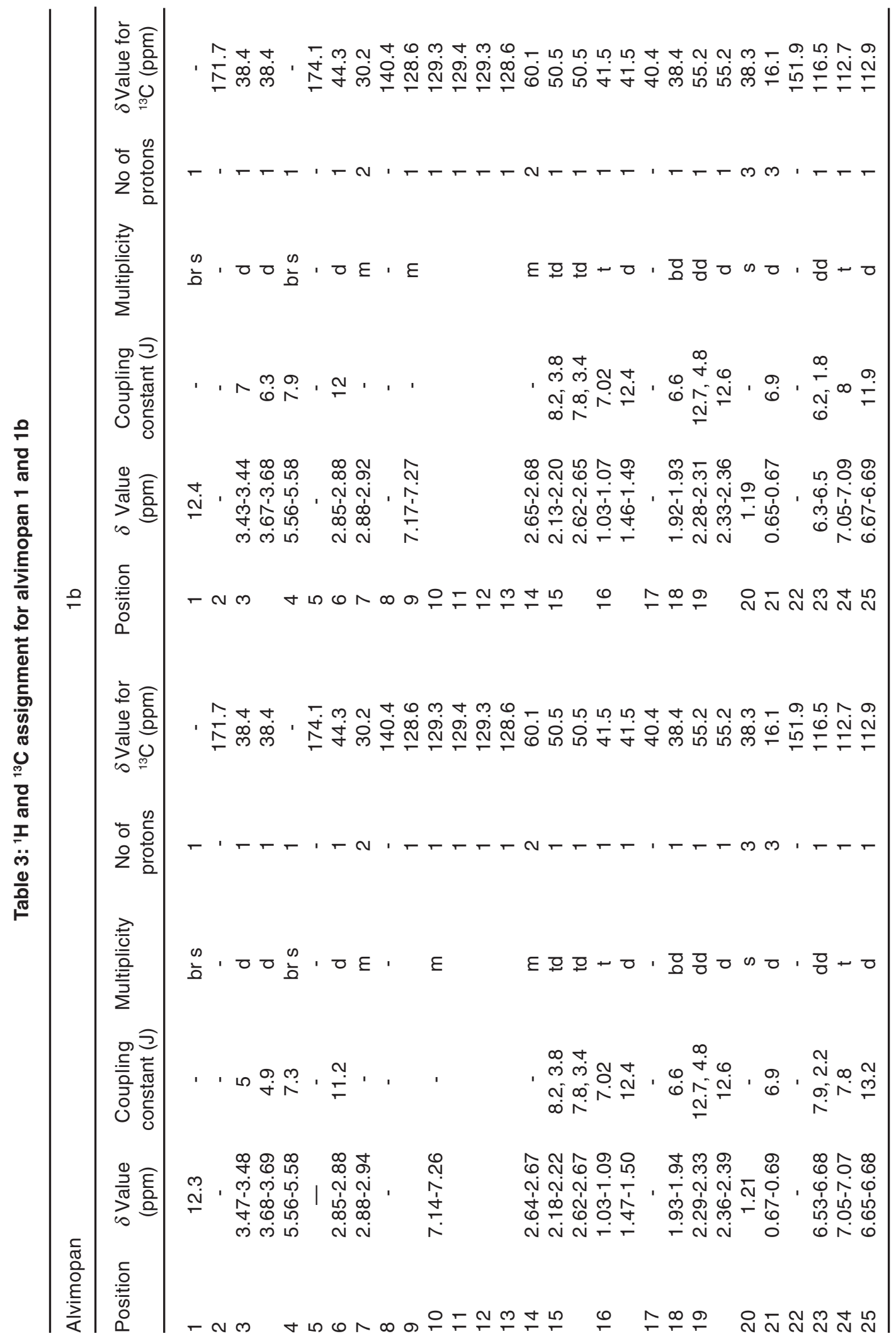




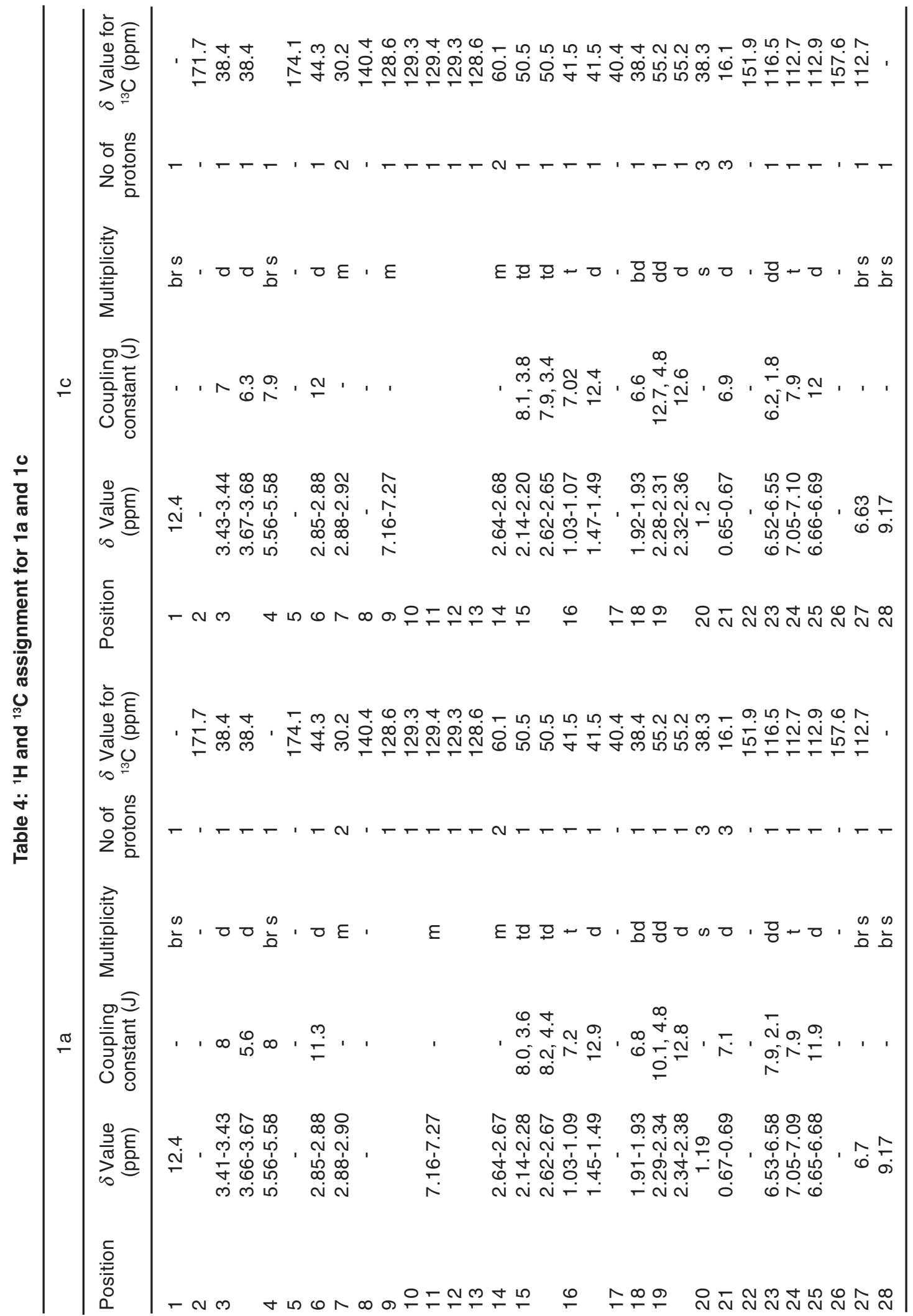


of carboxylic acid group, other broad band at 3207 $\mathrm{cm}^{-1}$ for amidic $\mathrm{NH}, 1682 \mathrm{~cm}^{-1}$ for carbonyl group of carboxylic acid and the broad band at $1590 \mathrm{~cm}^{-1}$ for carbonyl group of the amide group. The specific optical rotation of alvimopan $[\alpha]_{D}^{25}+43.48^{\circ}(\mathrm{C}=1.01$ DMSO). Based on the above spectral data the molecular formula of alvimopan was confirmed as $\mathrm{C}_{25} \mathrm{H}_{32} \mathrm{~N}_{2} \mathrm{O}_{4}$ and the corresponding structure was confirmed as ([[2(S)-[[4(R)-(3-Hydroxyphenyl)3R,4-dimethyl-1-piperidinyl]methyl]-1-oxo-3phenylpropyl]-amino]acetic acid.

\section{Compound 1a}

ESI mass spectrum of alvimopan impurity1 exhibited protonated molecule peak at $\mathrm{m} / \mathrm{z} 425$ $\left[(\mathrm{MH})^{+}\right]$in positive ion mode, indicating the mass of impurity-1 is 424 . In ${ }^{1} \mathrm{H}$ NMR of alvimopan impurity-1, the signal at $9.1 \mathrm{ppm}$ broad singlet corresponding to phenolic $\mathrm{OH}$ proton and another singlet at 5.56-5.58 ppm corresponds to amide proton of $\mathrm{NH}$. The complete NMR signals assignment was given in Table 4. In the IR spectrum, a broad band at $3423.5 \mathrm{~cm}^{-1}$ for $\mathrm{OH}$ of carboxylic acid group, other broad band at $3207.5 \mathrm{~cm}^{-1}$ for amidic $\mathrm{NH}, 1681 \mathrm{~cm}^{-1}$ for carbonyl group of carboxylic acid and the broad band at $1593.2 \mathrm{~cm}^{-1}$ for carbonyl group of the amide group. The specific optical rotation of alvimopan $[\alpha]^{25}{ }_{\mathrm{D}}+53.21^{\circ}(\mathrm{C}=1.01$ DMSO). Based on the above spectral data the molecular formula of alvimopan impurity1(compound1a) was confirmed as $\mathrm{C}_{25} \mathrm{H}_{32} \mathrm{~N}_{2} \mathrm{O}_{4}$ and the corresponding structure was confirmed as ([[2(S)-[[4(R)-(3-Hydroxyphenyl)-3R,4-dimethyl-1piperidinyl]methyl]-1-oxo-3-phenylpropyl]amino]acetic acid.

\section{Compound 1b}

ESI mass spectrum of alvimopan impurity-1 exhibited protonated molecule peak at $\mathrm{m} / \mathrm{z} 425$ $\left[(\mathrm{MH})^{+}\right]$in positive ion mode, indicating the mass of impurity-2 is 424 . In ${ }^{1} \mathrm{H}$ NMR of alvimopan impurity-2, the signal at $9.17 \mathrm{ppm}$ broad singlet corresponding to phenolic $\mathrm{OH}$ proton and another singlet at 5.56-5.58 ppm corresponds to amide proton of $\mathrm{NH}$. The complete NMR signals assignment was given in table-3. In the IR spectrum, a broad band at $3410.5 \mathrm{~cm}^{-1}$ for $\mathrm{OH}$ of carboxylic acid group, other broad band at $3209.5 \mathrm{~cm}^{-1}$ for amidic $\mathrm{NH}, 1592.2 \mathrm{~cm}^{-1}$ for carbonyl group of carboxylic acid and the broad band at $1682.3 \mathrm{~cm}^{-1}$ for carbonyl group of the amide group. The specific optical rotation of alvimopan $[\alpha]^{25}-47.22^{\circ}(\mathrm{C}=1.01$ DMSO). Based on the above spectral data the molecular formula of alvimopan impurity-2 was confirmed as $\mathrm{C}_{25} \mathrm{H}_{32} \mathrm{~N}_{2} \mathrm{O}_{4}$ and the corresponding structure was confirmed as ([[2(R)-[[4(S)-(3Hyd roxy phen yl) - $3 S, 4$ - di met hyl - 1 piperidinyl]methyl]-1-oxo-3-phenylpropyl]amino]acetic acid.

\section{Compound $1 \mathrm{C}$.}

ESI mass spectrum of alvimopan impurity-3 exhibited protonated molecule peak at $\mathrm{m} / \mathrm{z} 425$ $\left[(\mathrm{MH})^{+}\right]$in positive ion mode, indicating the mass of impurity-3 is 424 . In ${ }^{1} \mathrm{H}$ NMR of alvimopan impurity-3, the signal at $9.17 \mathrm{ppm}$ broad singlet corresponding to phenolic $\mathrm{OH}$ proton and another singlet at 5.56-5.58 ppm corresponds to amide proton of $\mathrm{NH}$. The complete NMR signals assignment was given in Table 4. In the IR spectrum, a broad band at $3425.6 \mathrm{~cm}^{-1}$ for $\mathrm{OH}$ of carboxylic acid group, other broad band at $3209 \mathrm{~cm}^{-1}$ for amidic $\mathrm{NH}, 1682 \mathrm{~cm}^{-1}$ for carbonyl group of carboxylic acid and the broad band at $1593.2 \mathrm{~cm}^{-1}$ for carbonyl group of the amide group. The specific optical rotation of alvimopan $[\alpha]^{25}-52.40^{\circ}(\mathrm{C}=1.01 \mathrm{DMSO})$. Based on the above spectral data the molecular formula of alvimopan impurity-3 was confirmed as $\mathrm{C}_{25} \mathrm{H}_{32} \mathrm{~N}_{2} \mathrm{O}_{4}$ and the corresponding structure was confirmed as ([[2(S)-[[4(S)-(3-Hydroxyphenyl)3S,4-dimethyl-1-piperidinyl]methyl]-1-oxo-3phenylpropyl]-amino]acetic acid.

\section{CONCLUSION}

The diastereomeric impurities of alvimopan were prepared and characterized by HPLC, Mass, IR, SOR and NMR $\left({ }^{1} \mathrm{H},{ }^{13} \mathrm{C}\right)$ techniques. The contents of these impurities were also identified in the alvimopan API and analytical method validation was concluded based on these.

\section{ACKNOWLEDGEMENT}

The authors wish to thank the management of Dr. Reddy's Laboratories Ltd., for supporting this work and co-operation from the other colleagues also highly appreciated. 


\section{REFERENCES}

1. a) Farrer, J. J.; Novel methods and compositions involving opioids and antagonists thereof, W.O., 2001, 037785 A2. b) Zimmerman, D. M.; Charles, H. M.; Piperidine opioid antagonists, U.S. Patent., 1990, 4891379A. c) Charles, B. J.; Process for preparing picenadol precursors and novel intermediates thereof, U.S. Patent., 1986, 4581456.

2. Centrell, B. E.; Zimmerman, D. M.; Peripherally selective piperidine carboxylate opioid antagonists, U.S. Patent., 1993, 5250542A.

3. Frank, S. A.; Prather, D. E.; Ward, J. A.; Werner, J. A.; Preparation of 3, 4, 4trisubstituted piperidinl-N-alkylcarboxylates and intermediates, U.S. Patent., 1995, 5434171.
4. Bourdonnec, B. L.; Dolle, R. E.; Process for the preparation of peripheral opioid antagonist compounds and intermediates thereto, U.S. Patent., 2004, 6794510B2.

5. CN Patent., 2006, 1827598A.

6. Reddy, B. R.; Reddy, K. S.; Dubey, M. K.; Kumari, B. Y.; Bandichhor, R.; Improved process for preparation of (3R,4R)-3-(3,4Dimethyl)-4-piperidinyl)phenol, a key intermediate for the synthesis of Alvimopan, Org. Process Res. Dev., 2014, 18(1), 163-167.

7. Werner, J. A.; Cerbone, L. R.; Frank, S. A.; Ward, J. A.; Labib, P.; Tharp-Taylor, R. W.; Ryan, C. W.; Synthesis of trans-3,4-Dimethyl -4-(3-hydroxyphenyl)piperidine. Opioid antagonist: Application of the Cis-thermal elimination of carbonates to alkaloid synthesis. J. Org. Chem., 1996, 61, 587-597. 